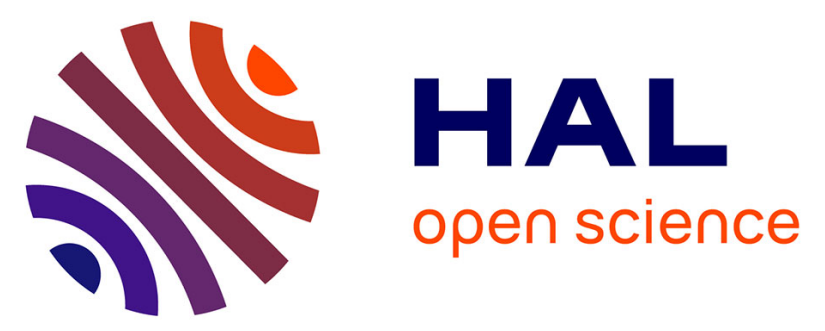

\title{
Recently approved antibacterials for methicillin-resistant Staphylococcus aureus (MRSA) and other Gram-positive pathogens: the shock of the new
}

Michael Z. David, Matthew Dryden, Thomas Gottlieb, Pierre Tattevin, Ian M. Gould

\section{To cite this version:}

Michael Z. David, Matthew Dryden, Thomas Gottlieb, Pierre Tattevin, Ian M. Gould. Recently approved antibacterials for methicillin-resistant Staphylococcus aureus (MRSA) and other Grampositive pathogens: the shock of the new. International Journal of Antimicrobial Agents, 2017, 50 (3), pp.303 - 307. 10.1016/j.ijantimicag.2017.05.006 . hal-01697318

HAL Id: hal-01697318

https://hal-univ-rennes1.archives-ouvertes.fr/hal-01697318

Submitted on 31 Jan 2018

HAL is a multi-disciplinary open access archive for the deposit and dissemination of scientific research documents, whether they are published or not. The documents may come from teaching and research institutions in France or abroad, or from public or private research centers.
L'archive ouverte pluridisciplinaire HAL, est destinée au dépôt et à la diffusion de documents scientifiques de niveau recherche, publiés ou non, émanant des établissements d'enseignement et de recherche français ou étrangers, des laboratoires publics ou privés. 
1 Recently approved antibacterials for MRSA and other gram-positive pathogens: The shock of

2 the new

3 Article Category: Review

4

$5 \quad$ Michael Z. David ${ }^{1}$, Matthew Dryden ${ }^{2}$, Thomas Gottlieb ${ }^{3}$, Pierre Tattevin ${ }^{4}$, Ian M. Gould ${ }^{5}$

$6{ }^{1}$ Department of Medicine, University of Chicago, Chicago, IL, USA; ${ }^{2}$ Department of

7 Microbiology and Communicable Diseases, Royal Hampshire County Hospital, Winchester,

8 Hampshire, UK; ${ }^{3}$ Department of Microbiology and Infectious Diseases, Concord Repatriation

9 General Hospital, Sydney, Australia; ${ }^{4}$ Infectious Diseases and Intensive Care Unit,

10 Pontchaillou University Hospital, Rennes, France; ${ }^{5}$ Medical Microbiology Department,

11 Aberdeen Royal Infirmary, UK.

12 Corresponding Author:

13 Michael Z. David, M.D., Ph.D.

14 The University of Chicago, Department of Medicine

155841 S. Maryland Ave., MC6054

16 Chicago, IL 60637

17 (voice) 773-702-3904; (fax) 773-702-1196

18 (e-mail)mdavid@medicine.bsd.uchicago.edu 
- Tedezolid, Dalbavancin, Ceftaroline, Ceftobiprole and Oritavancin are new agents

- All 5 drugs are broadly effective against Gram positive bacteria

- They will likely have important roles in therapy of multidrug-resistant infections

- Not yet approved for treatment of most invasive infections

- Monitoring for unanticipated adverse effects and resistance will be essential

\section{Abstract}

A number of novel antimicrobial drugs with activity against Gram positive bacterial pathogens have been licensed in the past four years. These drugs have the potential to enrich the group of intravenous drugs already available that are in common use against methicillin resistant Staphylococcus aureus, vancomycin resistant Enterococcus, and other antibiotic resistant Gram positive pathogens. The advantages and disadvantages of these drugs are not yet fully realized. Here we review the five most promising newly approved compounds: ceftaroline, ceftobiprole, oritavancin, dalbavancin and tedizolid. The advantages of their dosing regimens, their mechanisms of action, adverse effect profiles, evidence for their clinical usefulness, and the unique characteristics that distinguish them from one another and from older drugs are reviewed.

\section{Keywords}


44 Dalbavancin

45 Ceftaroline

46 Oritavancin

47 


\subsection{Introduction}

With the emergence of methicillin-resistant Staphylococcus aureus (MRSA) in the health care setting initially in the United Kingdom in 1960, and then in the community beginning in the 1990s [1], the limitations of vancomycin or teicoplanin as a primary therapy for severe and life-threatening MRSA infections have raised concern [2, 3]. MRSA, which is constitutively resistant to conventional $\beta$-lactam antibiotics, including penicillins and cephalosporins, has variable susceptibility to other classes of older antimicrobial agents, such as trimethoprim, sulfonamides, rifampicin, sodium fusidate, tetracyclines, and lincosamides [4]. Therefore, for severe or life-threatening infections, particularly when empiric therapy is needed, it is essential that patients receive a reliable alternative to these older agents.

The oxazolidinone linezolid [5, 6], the cell-wall active lipopeptide daptomycin [7], and the minocycline derivative tigecycline [8] have now been in widespread use for longer than a decade. They have served as alternative agents to the "standard" broad-spectrum IV therapies directed toward antibiotic resistant Gram positive pathogens, vancomycin and teicoplanin. The place of these drugs in the therapy of MRSA and vancomycin-resistant Enterococcus (VRE) infections has become established in practice although their roles can still be debated. The initial enthusiasm for tigecycline was diminished after it received a black-box warning from the U.S. Food and Drug Administration (FDA) in September 2013 for an increased risk of death relative to comparator drugs noted in pooled data from 13 phase 3 and 4 trials (http://www.fda.gov/drugs/drugsafety/ucm369580.htm). However, tigecycline may still play a role in combination therapy in multidrug-resistant Gram negative infections.

The value of combination therapy for $S$. aureus, including a possible advantage of glycopeptides with $\beta$-lactams, remains uncertain, and is the subject of a large multicenter, randomized, controlled trial (RCT) in patients with $S$. aureus bacteraemia [9]. The results of 
this study, as well as further data from observational studies using daptomycin and linezolid for invasive infections, are eagerly anticipated.

Since 2013, a number of newer antimicrobial agents were approved by North

American and European regulatory agencies for the treatment of MRSA and other multidrugresistant Gram positive pathogens. The place of these agents in the therapeutic armamentarium in a rapidly changing epidemiologic MRSA and VRE infection landscape, which varies from continent to continent, is not yet determined. These drugs were generally approved for the treatment of complicated soft tissue infections alone, or less commonly also for pneumonia. Therefore, their efficacy and safety in the therapy of unapproved, invasive infections, such as bacteraemia, osteomyelitis, and endocarditis, where they may have a more important niche to fill, has not been demonstrated. Each drug has certain advantages compared with older drugs. Here we review these advantages, but also the adverse effects, the mechanisms, the limited evidence for their clinical usefulness, and the unique characteristics of the most promising five drugs among those recently approved. They may play a role in the therapy of MRSA and VRE infections, among other multidrug resistant Gram positive pathogens, in the coming years.

\subsection{Tedizolid (Sivextro)}

This new oxazolidinone has a licence for short course ( 6 days) treatment, both intravenous (IV) and oral, to manage acute bacterial skin and skin structure infections (ABSSSI). Possible advantages over linezolid include less monoamine oxidase (MAO) inhibition and serotonergic interactions, less myelosuppression, less neuropathy [10, 11], less development of spontaneous resistance, less susceptibility to the cfr mobile resistance 
mechanism and cidality of intracellular bacteria. Possible disadvantages are a high price and limited experience with prolonged dosing schedules.

As with linezolid, tedizolid acts by binding to $23 \mathrm{~S}$ ribosomal RNA of the $50 \mathrm{~S}$ subunit, suppressing protein synthesis. It is administered as a microbiologically inactive prodrug improving absorption (91\%) [12], which is rapidly converted in the body into active tedizolid. Its hydroxymethyl group is masked from MAO by this prodrug formulation. As an inherently more active molecule than linezolid with improved ribosomal binding (due to novel C and D rings), it can be administered in lower doses and possibly in shorter courses which should have ecological benefits and select less for resistance, a point suggested by in vitro studies $[13,14]$. A $12 \mathrm{~h}$ half-life allows for once a day dosing. Susceptibility to linezolid in S. aureus is likely a reliable proxy for tedizolid susceptibility [15]. Although susceptible to ribosomal mutations, tedizolid is not, as yet, inactivated by cfr methyl transferase which inactivates linezolid [16-18]. Its concentrations in macrophages seems to lead to intracellular killing of staphylococci which offers potential for preventing infection relapse due to small colony variants. Spectrum of activity includes most Gram positive bacteria, including anaerobes, streptococci, staphylococci (coagulase positive and negative) and enterococci. Activity against MRSA equates to that against methicillin-susceptible S. aureus (MSSA). There is rapid tissue distribution, no dosage adjustment in renal or liver failure, protein binding of $70-90 \%,>80 \%$ elimination via the liver and no metabolic drug interactions. The registration studies, ESTABLISH 1 and 2 showed significantly less gastrointestinal adverse events and less platelet suppression than linezolid [10, 11].

Tedizolid was approved by the U.S. FDA in June 2014 for ABSSSIs and by the European Medicine Agency (EMA), and Canada in March 2015 and should allow for earlier hospital discharge of patients and perhaps an entirely community-based treatment schedule 
for severe ABSSSI. Experience will tell whether it lives up to its promises, particularly of less resistance selection, less toxicity and less drug interaction. If so, then it may be useful for long term treatment of bone, joint and central nervous system infection, which are often related to foreign bodies, including prostheses, and even as a short term alternative to linezolid where toxicity or drug interaction precludes the latter's use. Recent data confirm lack of bone marrow suppression after 3 weeks of the licensed 200-mg dose [19]. Trials in pneumonia are underway.

\subsection{Oritavancin}

Oritavancin is a vancomycin-derived semisynthetic lipoglycopeptide antibiotic with several mechanisms of action. The unique feature, along with dalbavancin, is an extended plasma half-life, resulting in single-dose treatment regimens. It may provide a new challenge to established practice, in the first instance for outpatient management of ABSSSIs [20, 21].

Two similarly conducted phase III randomized controlled trials (RCTs), SOLO I and II, of single dose IV oritavancin, $1200 \mathrm{mg}$ infused over $3 \mathrm{~h}$ in adult ABSSSI patients, demonstrated non-inferiority when compared with 7-10 days of vancomycin therapy [22, 23]. This was unaffected by patient body mass index. Response rates were equivalent for MSSA and MRSA.

Oritavancin displays concentration-dependent bactericidal activity, with a $\mathrm{C}_{\max }$ of $\sim 28.5 \mathrm{mg} / \mathrm{L}$, extensive tissue distribution, $\sim 90 \%$ protein binding with slow elimination and half-life $>250 \mathrm{~h}$, without dose adjustment requirements for renal or moderate hepatic impairment. It achieves high intracellular concentrations and is active against small colony variants and bacteria in stationary phase [20, 21]. Intermittent dosing with oritavancin could 
potentially be an ideal addition for treatment of osteomyelitis or biofilm-related infection, but efficacy data for these conditions are lacking. Indeed osteomyelitis was an exclusion criterion in registration trials (and though already likely pre-existing in these patients), was noted as an adverse event in $0.3 \%$ [23].

Oritavancin has activity against Staphylococcus aureus, invasive $\beta$-haemolytic streptococci (Group A, B, C and G), S. anginosus, S. pneumoniae, Enterococcus faecalis and E. faecium. It moreover has extended activity against MRSA (mecA and mecC), hVISA, and van A-, vanB- and vanC-encoded resistance [24], with activity (MICs $\leq 0.12 \mu \mathrm{g} / \mathrm{mL}$ ) against daptomycin non-susceptible VRE (daptomycin MIC >4 $\mu \mathrm{g} / \mathrm{mL}$ ) [24].

In the SOLO II study, $73 \%$ of infections were due to S. aureus, but only $25 \%$ had a white blood cell count >12,000 cells/uL and only 10/340 were bacteraemic [23]. By inference, these were not severely ill patients, and conceivably many such patients could also be treated with drainage and oral antibiotic therapy [25]. As the RCTs may not have included patients with more severe infections, prospective clinical trial efficacy data will be valuable. ABSSSIs are currently the only approved clinical indication for oritavancin, and clinical use will therefore be focused on S. aureus, more specifically MRSA infection. The role for oritavancin in the management of infections by other resistant Gram positive organisms, and infections at other anatomic sites, is undetermined.

There are numerous potential benefits by the elimination of multidose and multiday regimens. These include reduced complications of cannulation, such as catheter-associated bacteraemia; reduced hospitalisation and health care resource utilisation; no requirement for ongoing drug concentration monitoring or dose adjustment; and a decrease in noncompliance. 
stewardship; many of these challenges will also be true for dalbavancin as noted below.

There is no de-escalation. Use as empiric therapy may result in commitment to a drug that diagnostic tests may subsequently confirm as unnecessary or inappropriate, while prescribing delays would diminish some of its inherent advantages. Absence of a functioning outpatient treatment service may limit the utility of this agent. There are well-evaluated pre-existing oral antibiotics available for the majority of non-invasive $S$. aureus infections, including MRSA infections, (e.g., clindamycin and trimethoprim-sulfamethoxazole), and which can, moreover, hasten an intravenous-to-oral switch. The high acquisition cost, estimated at 2900 U.S. dollars [26] may be a disincentive.

Prior experience indicates that antibiotic resistance follows an antimicrobial's introduction into the clinical arena. Although lipoglycopeptide resistance has not been reported, trailing oritavancin and dalbavancin levels may encourage the development of resistance. It will also be important to recognise patients with glycopeptide allergies. Fortunately, hypersensitivity is uncommon for vancomycin and the range of adverse events were minor for both drugs after 60-day follow-up [22, 23]. Nonetheless, occurrence of severe hypersensitivity in long half-life drugs could deliver a difficult management scenario. Oritavancin, similar to dalbavancin (described below) is an innovative development which avoid misplaced use.

\subsection{Dalbavancin} natural antibiotic produced by Nonomuria spp. Its structure has been altered to enhance 
activity against $S$. aureus, and to extend its half-life [27]. The minimum inhibitory concentration (MIC) breakpoint was defined as $0.0125 \mathrm{mg} / \mathrm{L}$ by the FDA, with $\mathrm{MIC}_{50}$ and $\mathrm{MIC}_{90}$ of $0.06 \mathrm{mg} / \mathrm{L}$ for MSSA as well as MRSA. Dalbavancin interacts with terminal Dalanyl-D-alanine residues of peptidoglycan precursors, and inhibits both transpeptidase and transglycosylase [28]. Dalbavancin is 95\% protein-bound, with an elimination half-life of 346 $\mathrm{h}$ (14.5 days). After a single 1000-mg infusion, the serum level peaks at $>200 \mathrm{mg} / \mathrm{L}$ and is still $>20 \mathrm{mg} / \mathrm{L}$ at day 7 . Dose adjustment is recommended in patients with creatinine clearance $<30 \mathrm{~mL} / \mathrm{min}$. Dalbavancin does not interact with the P450 metabolic pathway [29]. Most randomized trials evaluated the dosage of $1000 \mathrm{mg}$ on day 1 followed by 500 mg on day 8. One phase II trial found that dalbavancin was at least as effective as vancomycin for uncomplicated, catheter-related bloodstream infections due to Gram positive bacteria [30]. Two phase III studies, DISCOVER 1 and DISCOVER 2, demonstrated that dalbavancin was non-inferior to comparators (vancomycin/linezolid) in ABSSSI, with a $79.7 \%$ success rate with dalbavancin $(n=659)$ vs. $79.8 \%$ with comparators $(95 \%$ confidence interval difference, -4.5 to $4.2 \%$ ) [31].

Strengths of dalbavancin include activity against more than $99 \%$ of clinical MRSA isolates, including VISA (4-8 times more active than vancomycin in vitro); convenient dosage due to an extended half-life with an FDA-approved regimen of $1000 \mathrm{mg}$ on day 1 followed by $500 \mathrm{mg}$ on day 8 ; the potential for a single $1500 \mathrm{mg}$ dose also shown to be effective for ABSSSI [32]; concentrations similar to plasma levels in numerous tissues, including bones (above staphylococcal $\mathrm{MIC}_{90} 14$ days after a single 1000-mg infusion [33]); and a satisfactory safety profile with no nephrotoxicity [34].

Despite the potential advantages that the long half-life afford this drug, there are also weaknesses that must be noted. Many of the weakness are the same as for oritavancin, noted 
above. The susceptibility of $S$. aureus is reduced in isolates with reduced susceptibility to vancomycin; some limitations in efficacy have been suggested in experimental animal studies (e.g., it was not bactericidal in the rabbit model of endocarditis [35], and it was unable to eradicate adherent MRSA in a foreign-body infection model in guinea pigs [36]); clinical data in humans remain largely limited to non-inferiority trials in patients with ABSSSI; high cost; and the extended terminal half-life may be detrimental in case of a severe adverse event. The drug is not cleared by haemodialysis, making it difficult to reverse in such cases.

Dalbavancin is FDA-approved only to treat ABSSSI due to Gram positive bacteria.

However, both dalbavancin and oritavancin have great promise, pending the accumulation of additional data, to treat invasive infections that now require long-term intravenous therapy with other drugs, such as vancomycin or daptomycin. These might include MRSA bloodstream infections (including catheter-related infections), bone and joint infections (including prosthetic joints), and endocarditis.

How dalbavancin compares with oritavancin with the accumulation of clinical experience may demonstrate important differences in efficacy or adverse reactions. Thus careful monitoring of their strengths and weaknesses will be essential to the establishment of their respective roles in empiric and definitive therapeutic regimens. Both of the novel longacting drugs may enable a remarkable shift in the approach to treating multidrug-resistant Gram positive invasive infections in the outpatient setting. As for oritavancin, this is likely to decrease noncompliance, decrease the overall costs compared with more frequently dosed drugs, obviate the need for the monitoring of drug levels, make possible earlier discharge from hospitals, and prevent the complications associated with indwelling outpatient intravenous catheters. 


\subsection{Novel Cephalosporins (Ceftaroline and Ceftobiprole)}

Ceftaroline and ceftobiprole are the only B-lactams with the property of additional coverage against both hospital- and community-acquired MRSA with activity extending to $S$. aureus with reduced susceptibility to vancomycin $[37,38]$. Both antibiotics have similar broad-spectrum activity, retaining bactericidal activity against not only Gram positive but also Gram negative organisms. Being ß-lactams, they have a relatively mild side effect profile, similar to other cephalosporins.

Like all other $\beta$-lactam antibiotics, they are bactericidal, binding to penicillin-binding proteins (PBPs) of susceptible organisms to interfere with cell wall synthesis. In contrast to traditional ß-lactam agents, they have high binding affinity for PBP-2a, which gives them unique bactericidal activity against nearly all strains of methicillin-resistant staphylococci. They also show increased binding affinity for PBP-2x, a PBP modification seen in ß-lactam resistant Streptococcus pneumoniae [37]. The efficacy and safety of ceftaroline was assessed in two large phase III RCTs for community-acquired pneumonia (CAP) (FOCUS $1 \& 2$ studies) and ABSSSIs (CANVAS $1 \& 2$ studies) $[39,40]$. For both indications, ceftaroline was observed to be non-inferior to the comparator agents (ceftriaxone for CAP and vancomycin plus aztreonam for ABSSSIs) at both a standard test of cure assessment time (815 days after discontinuation of study drug) and an early assessment time point (day 3 or 4 of study). Early response [39] may facilitate decisions to de-escalate antibiotic treatment to a narrower-spectrum agent, switch from IV to oral therapy and discharge of a patient based on clinical improvement. The adverse effect profile of ceftaroline in the registration trials was comparable to other cephalosporins.

The recommended standard dose of ceftaroline in adult patients with adequate renal function is $600 \mathrm{mg}$ IV 12 hourly infused over 60 minutes. In patients with impaired renal function, the dose is reduced. There may be a case for increasing the dose frequency in 
pneumonia and bacteraemia. A recent trial has shown that an 8 hourly dosing regimen does not confer any benefit over a 12-h regimen in patients with sepsis [41]. For the two approved indications, the duration of ceftaroline therapy is 5-14 days for ABSSSIs and 5-7 days for CAP.

Ceftaroline is likely to be combined with the $\beta$-lactamase Avibactam which will extend the spectrum of activity to include Enterobacteriaceae that express extended spectrum B-lactamases, including AmpC B-lactamases [42].

Ceftobiprole has a similar spectrum to ceftaroline, and excludes clinical activity against extended-spectrum B-lactamase-producing Gram negatives and Pseudomonas aeruginosa. Ceftobiprole has received national licenses for the treatment of adult patients with CAP and hospital-acquired pneumonia, excluding ventilator-associated pneumonia, in most European countries and Canada, but not yet in the U.S. Ceftobiprole medocaril, the prodrug of ceftobiprole, is converted by plasma esterases to ceftobiprole in $<30$ minutes. Peak serum concentrations of ceftobiprole observed at the end of a single 30-minute infusion were $35.5 \mu \mathrm{g} / \mathrm{mL}$ for a $500-\mathrm{mg}$ dose and $59.6 \mu \mathrm{g} / \mathrm{mL}$ for a $750-\mathrm{mg}$ dose. Protein binding is $16 \%$, and its serum half-life is approximately $3.5 \mathrm{~h}$. Ceftobiprole is renally excreted, and systemic clearance correlates with creatinine clearance; therefore, dosage adjustment is required in patients with renal dysfunction [38].

Currently, only limited clinical trial data are published for ceftobiprole [43, 44]. A phase III RCT compared ceftobiprole 500 mg every 8 h with vancomycin 1 g every 12 h plus ceftazidime $1 \mathrm{~g}$ every $8 \mathrm{~h}$ in patients with complicated skin and skin structure infections. Of the 828 subjects, $31 \%$ had diabetic foot infections, $30 \%$ had abscesses, and $22 \%$ had wounds. No difference in clinical cure was reported in the clinically evaluable, intent-to-treat and microbiologically evaluable populations with cure rates of $90.5 \%, 81.9 \%$, and $90.8 \%$, 
respectively, in the ceftobiprole-treated patients and $90.2 \%, 80.8 \%$, and $90.5 \%$, respectively, in the vancomycin plus ceftazidime-treated group [43].

The clinical role for these novel cephalosporins has been debated [45]. As B-lactam antibiotics, the class is tried and tested. They have activity against all methicillin-resistant staphylococci, and have all the advantages of a $\beta$-lactam: familiarity of use over many decades, good tolerability and low rate of adverse effects. They also have activity against penicillin-resistant pneumococci and so have a role for treating CAP where such organisms are prevalent. Their antistaphylococcal activity extends to heteroresistant, vancomycinintermediate, vancomycin-resistant and daptomycin-nonsusceptible isolates of both coagulase-positive and -negative species. They may have roles in the treatment of complex infections such as endocarditis, osteomyelitis and prosthetic device infections. Resistance to ceftaroline, related to alterations in PBP2a, has been identified in MRSA; several studies have suggested that resistance is especially common in ST239 MRSA, a healthcareassociated strain type that predominates in many countries of the world [46, 47]. A mechanism of resistance to ceftaroline independent of PBP-2a sequence, linked to a mutation in PBP4, has also been detected [48].

The two broad-spectrum cephalosporins may also have a role in the empirical treatment of patients with comorbidities who may be infected with MRSA. In these patients it is reassuring to have the possibility of using a broad spectrum B-lactam with activity against MRSA, as in complex skin and soft tissue infection and surgical or traumatic wound infections. The registration trials showed that there may be an early response in defervescence of fever and reduction in inflammation with ceftaroline [39]. As for other Blactams, the pharmacokinetics are favourable, with good serum and cerebrospinal fluid levels, suggesting that these agents are suitable for treating bacteraemia and suspected meningitis 
alone or in combination. Ceftaroline has also been used in combination with daptomycin as a potent and effective treatment for complex MRSA sepsis [49].

\subsection{Conclusion}

These novel agents may take on important roles in the therapy of multidrug-resistant, invasive infections, particularly those caused by MRSA and VRE. The lack of approved indications for treatment of invasive infections, however, may slow the introduction of the novel agents for severe disease. In addition, the emergence of resistance in MRSA and VRE to each of these new drugs must be monitored, as resistance has emerged to all previously introduced antistaphylococcal drugs [4]. Resistance has already been identified in MRSA to each of the described drugs, but now remains relatively rare. Future trials for additional indications and monitoring for unanticipated adverse effects will be essential to establish the optimal roles for these newly approved drugs, particularly in regions with a low incidence of MRSA infection.

\section{Declarations}

Funding: This research did not receive any specific grant from funding agencies in the public, commercial, or not-for-profit sectors.

Competing Interests: MZD has no potential conflicts of interest to report. MD has served on advisory boards or received honoraria for lectures from Pfizer, Bayer, MSD, AstraZeneca, Cubist and The Medicines Company. TG reports that within the past 3 years serving on advisory boards for MSD, Pfizer and Astra-Zeneca. PT has received support from AstraZenica, Basilea, The Medicines Company, and MSD, for consultancies or travel to meetings and accommodation. IMG reports receiving consultancy and/or lecture fees from AstraZeneca, Basilea, Bayer, Clinigen, Cubist, MSD, Novartis, Pfizer and The Medicines 
335 Company. In his capacity as President of the International Society of Chemotherapy, IMG

336 frequently requests meeting support from a wide range of diagnostic and pharmaceutical

337 companies, including many of those involved in the manufacture of diagnostics and

338 antibacterials for MRSA.

339 Ethical Approval: Ethical approval was not required for this study. 
1. Chambers HF, Deleo FR. Waves of resistance: Staphylococcus aureus in the antibiotic era. Nat Rev Microbiol 2009;7:629-41. doi:10.1038/nrmicro2200.

2. Rubinstein E, Keynan Y. Vancomycin revisited - 60 years later. Front Public Health 2014;2:217. doi: 10.3389/fpubh.2014.00217.

3. Gardete S, Tomasz A. Mechanisms of vancomycin resistance in Staphylococcus aureus. J Clin Invest 2014;124:2836-40. doi: 10.1172/JCI68834.

4. Lowy FD. Antimicrobial resistance: the example of Staphylococcus aureus. J Clin Invest $2003 ; 111: 1265-73$.

5. Watkins RR, Lemonovich TL, File TM Jr. An evidence-based review of linezolid for the treatment of methicillin-resistant Staphylococcus aureus (MRSA): place in therapy. Core Evid 2012;7:131-43. doi: 10.2147/CE.S33430.

6. Wilcox M, Nathwani D, Dryden M. Linezolid compared with teicoplanin for the treatment of suspected or proven Gram-positive infections. J Antimicrob Chemother 2004;53:335-44. therapy for Gram-positive infections. Int J Antimicrob Agents 2013;42:202-10. doi: 10.1016/j.ijantimicag.2013.05.005.

8. Dryden M. Tigecycline: an antibiotic for the twenty-first century. J Antimicrob Chemother 2013;68 Suppl 2:ii3-4. doi: 10.1093/jac/dkt139. 
361

362

363

364

365

366

367

368

369

370

371

372

373

374

375

376

377

378

379

380

381

infection: study protocol for a randomised controlled trial. Trials 2016;17:170. doi: 10.1186/s13063-016-1295-3.

10. Prokocimer P, De Anda C, Fang E, Mehra P, Das A. Tedizolid phosphate vs linezolid for treatment of acute bacterial skin and skin structure infections: the ESTABLISH-1 randomized trial. JAMA 2013;309:559-69. doi:10.1001/jama.2013.241

11. Moran GJ, Fang E, Corey GR, Das AF, De Anda C, Prokocimer P. Tedizolid for 6 days versus linezolid for 10 days for acute bacterial skin and skin-structure

infections (ESTABLISH-2): a randomised, double-blind, phase 3, non-inferiority

trial. Lancet Infect Dis 2014;14:696-705. doi: 10.1016/S1473-3099(14)70737-6.

12. Flanagan SD, Bien PA, Muñoz KA, Minassian SL, Prokocimer PG. Pharmacokinetics of tedizolid following oral administration: single and multiple dose, effect of food, and comparison of two solid forms of the prodrug. Pharmacotherapy 2014;34:240-50. doi: 10.1002/phar.1337.

13. Shaw KJ, Poppe S, Schaadt R, Brown-Driver V, Finn J, Pillar CM, Shinabarger D, Zurenko G. In vitro activity of TR-700, the antibacterial moiety of the prodrug TR-701, against linezolid-resistant strains. Antimicrob Agents Chemother 2008;52:4442-7. doi: 10.1128/AAC.00859-08.

14. Locke JB, Finn J, Hilgers M, Morales G, Rahawi S, G C K, et al. Structure-activity relationships of diverse oxazolidinones for linezolid-resistant Staphylococcus aureus strains possessing the cfr methyltransferase gene or ribosomal mutations. Antimicrob Agents Chemother 2010;54:5337-43. doi: 10.1128/AAC.00663-10. 
382

383

384

385

386

387

388

389

390

391

392

393

394

395

396

397

398

399

400

401

402

15. Zurenko G, Bien P, Bensaci M, Patel HN, Thorne G. Use of linezolid susceptibility test results as a surrogate for the susceptibility of Gram-positive pathogens to tedizolid, a novel oxazolidinone. Ann Clin Microbiol Antimicrob 2014;13:46. doi: 10.1186/s12941-014-00460.

16. Russo A, Campanile F, Falcone M, Tascini C, Bassetti M, Goldoni P, et al. Linezolidresistant staphylococcal bacteraemia: A multicentre case-case-control study in Italy. Int J Antimicrob Agents 2015;45:255-61. doi: 10.1016/j.ijantimicag.2014.12.008.

17. Lee Y, Hong SK, Choi S, Im W, Yong D, Lee K. In vitro activity of tedizolid against gram-positive bacteria in patients with skin and skin structure infections and hospitalacquired pneumonia: a Korean multicenter study. Ann Lab Med 2015;35:523-30. doi: 10.3343/alm.2015.35.5.523.

18. Barber KE, Smith JR, Raut A, Rybak MJ. Evaluation of tedizolid against Staphylococcus aureus and enterococci with reduced susceptibility to vancomycin, daptomycin or linezolid. J Antimicrob Chemother 2016;71:152-5. doi: 10.1093/jac/dkv302.

19. Lodise TP, Bidell MR, Flanagan SD, Zasowski EJ, Minassian SL, Prokocimer P.

Characterization of the haematological profile of 21 days of tedizolid in healthy subjects. $\mathbf{J}$ Antimicrob Chemother. 2016;71:2553-8. doi: 10.1093/jac/dkw206.

20. Saravolatz LD, Stein GE. Oritavancin: a long-half-life lipoglycopeptide. Clin Infect Dis 2015;61:627-32. doi: 10.1093/cid/civ311. 
403

404

405

406

407

408

409

410

411

412

413

414

415

416

417

418

419

420

421

422

423

21. Mitra S, Saeed U, Havlichek DH, Stein GE. Profile of oritavancin and its potential in the treatment of acute bacterial skin structure infections. Infect Drug Resist 2015;8:189-97. doi: 10.2147/IDR.S69412.

22. Corey GR, Kabler H, Mehra P, Gupta S, Overcash JS, Porwal A, et al. Single-dose oritavancin in the treatment of acute bacterial skin infections. N Engl J Med 2014;370:218090. doi: 10.1056/NEJMoa1310422.

23. Corey GR, Good S, Jiang H, Moeck G, Wikler M, Green S, et al. Single-dose oritavancin versus 7-10 days of vancomycin in the treatment of gram-positive acute bacterial skin and skin structure infections: the SOLO II noninferiority study. Clin Infect Dis 2015;60:254-62. doi: $10.1093 / \mathrm{cid} / \mathrm{ciu} 778$.

24. Biedenbach DJ, Arhin FF, Moeck G, Lynch TF, Sahm DF. In vitro activity of oritavancin and comparator agents against staphylococci, streptococci and enterococci from clinical infections in Europe and North America, 2011-2014. Int J Antimicrob Agents 2015;46:67481. doi: 10.1016/j.ijantimicag.2015.08.014.

25. Miller LG, Daum RS, Creech CB, Young D, Downing MD, Eells SJ, et al. Clindamycin versus trimethoprim-sulfamethoxazole for uncomplicated skin infections. N Engl J Med 2015;372:1093-103. doi: 10.1056/NEJMoa1403789.

26. Anon. Oritavancin (Orbactiv) for skin and skin structure infections. Med Lett Drugs Ther 2015;57:3-5.

27. Malabarba A, Goldstein BP. Origin, structure, and activity in vitro and in vivo of dalbavancin. J Antimicrob Chemother 2005;55 Suppl 2:ii15-20. 
28. Smith JR, Roberts KD, Rybak MJ. Dalbavancin: a novel lipoglycopeptide antibiotic with extended activity against Gram-positive infections. Infect Dis Ther 2015;4:245-58. doi: $10.1007 / \mathrm{s} 40121-015-0077-7$.

29. Dorr MB, Jabes D, Cavaleri M, Dowell J, Mosconi G, Malabarba A, et al. Human pharmacokinetics and rationale for once-weekly dosing of dalbavancin, a semi-synthetic glycopeptide. J Antimicrob Chemother 2005;55 Suppl 2:ii25-30.

30. Raad I, Darouiche R, Vazquez J, Lentnek A, Hachem R, Hanna H, et al. Efficacy and safety of weekly dalbavancin therapy for catheter-related bloodstream infection caused by gram-positive pathogens. Clin Infect Dis 2005;40:374-80.

31. Boucher HW, Wilcox M, Talbot GH, Puttagunta S, Das AF, Dunne MW. Once-weekly dalbavancin versus daily conventional therapy for skin infection. N Engl J Med 2014;370:2169-79.

32. Dunne MW, Puttagunta S, Giordano P, Krievins D, Zelasky M, Baldassarre J. A randomized clinical trial of single-dose versus weekly dalbavancin for treatment of acute bacterial skin and skin structure infection. Clin Infect Dis 2016;62:545-51. doi: 10.1093/cid/civ982.

33. Dunne MW, Puttagunta S, Sprenger CR, Rubino C, Van Wart S, Baldassarre J. Extendedduration dosing and distribution of dalbavancin into bone and articular tissue. Antimicrob Agents Chemother 2015;59:1849-55. doi: 10.1128/AAC.04550-14.

34. Dunne MW, Talbot GH, Boucher HW, Wilcox M, Puttagunta S. Safety of dalbavancin in the treatment of skin and skin structure infections: a pooled analysis of randomized, comparative studies. Drug Saf 2016;39:147-57. doi: 10.1007/s40264-015-0374-9. 
35. Lefort A, Pavie J, Garry L, Chau F, Fantin B. Activities of dalbavancin in vitro and in a rabbit model of experimental endocarditis due to Staphylococcus aureus with or without reduced susceptibility to vancomycin and teicoplanin. Antimicrob Agents Chemother 2004;48:1061-4.

36. Baldoni D, Furustrand Tafin U, Aeppli S, Angevaare E, Oliva A, Haschke M, et al. Activity of dalbavancin, alone and in combination with rifampicin, against meticillin-resistant Staphylococcus aureus in a foreign-body infection model. Int J Antimicrob Agents 2013;42:220-5. doi: 10.1016/j.ijantimicag.2013.05.019.

37. Garrison MW, Kawamura NM, Wen MM. Ceftaroline fosamil: a new cephalosporin active against resistant Gram-positive organisms including MRSA. Expert Rev Anti Infect Ther 2012;10:1087-103. doi: 10.1586/eri.12.112.

38. Zhanel GG, Lam A, Schweizer F, Thomson K, Walkty A, Rubinstein E, et al. Ceftobiprole: a review of a broad-spectrum and anti-MRSA cephalosporin. Am J Clin Dermatol 2008;9:245-54.

39. Friedland HD, O'Neal T, Biek D, Eckburg PB, Rank DR, Llorens L, et al. CANVAS 1 and 2: analysis of clinical response at day 3 in two phase 3 trials of ceftaroline fosamil versus vancomycin plus aztreonam in treatment of acute bacterial skin and skin structure infections. Antimicrob Agents Chemother 2012;56:2231-6. doi: 10.1128/AAC.05738-11.

40. Goodman JJ, Martin SI. Critical appraisal of ceftaroline in the management of community-acquired bacterial pneumonia and skin infections. Ther Clin Risk Manag 2012;8:149-56. doi: 10.2147/TCRM.S17413.

41. Dryden M, Wilson D, Iaconis J, Gonzalez J. A Phase III trial of ceftaroline fosamil 600 mg q8h versus vancomycin plus aztreonam in patients with cSSTI with systemic 
469 inflammatory response or underlying comorbidities. Abstracts of $25^{\text {th }}$ ECCMID 2015,

470 Copenhagen, Denmark, 27 April 2015, Abstract O193.

471 42. Castanheira M, Sader HS, Farrell DJ, Mendes RE, Jones RN. Activity of ceftaroline-

472 avibactam tested against Gram-negative organism populations, including strains expressing

473 one or more $\beta$-lactamases and methicillin-resistant Staphylococcus aureus carrying various

474 staphylococcal cassette chromosome mec types. Antimicrob Agents Chemother

475 2012;56:4779-85. doi: 10.1128/AAC.00817-12.

476

43. Noel GJ, Bush K, Bagchi P, Ianus J, Strauss RS. A randomized, double-blind trial

477 comparing ceftobiprole medocaril with vancomycin plus ceftazidime for the treatment of

478 patients with complicated skin and skin-structure infections. Clin Infect Dis 2008;46:647-55.

479 doi: $10.1086 / 526527$.

480

44. Noel GJ, Strauss RS, Amsler K, Heep M, Pypstra R, Solomkin JS. Results of a double-

481

blind, randomized trial of ceftobiprole treatment of complicated skin and skin structure

482

infections caused by gram-positive bacteria. Antimicrob Agents Chemother 2008;52:37-44.

483

45. Dryden MS. Alternative clinical indications for novel antibiotics licensed for skin and

soft tissue infection? Curr Opin Infect Dis 2015;28:117-24. doi:

485

10.1097/QCO.0000000000000142.

46. Long SW, Olsen RJ, Mehta SC, Palzkill T, Cernoch PL, Perez KK, et al. PBP2a

487

mutations causing high-level Ceftaroline resistance in clinical methicillin-resistant

488

Staphylococcus aureus isolates. Antimicrob Agents Chemother 2014;58:6668-74. doi:

489

10.1128/AAC.03622-14. 
490

491

492

493

494

495

496

497

498

499

500

47. Mubarak N, Sandaradura I, Isaia L, O'Sullivan M, Zhou F, Marriott D, et al. Nonsusceptibility to ceftaroline in healthcare-associated multiresistant MRSA in Eastern Australia. J Antimicrob Chemother 2015;70:2413-4. doi: 10.1093/jac/dkv124.

48. Greninger AL, Chatterjee SS, Chan LC, Hamilton SM, Chambers HF, Chiu CY. Wholegenome sequencing of methicillin-resistant Staphylococcus aureus resistant to fifthgeneration cephalosporins reveals potential non-mecA mechanisms of resistance. PLoS One 2016;11:e0149541. doi: 10.1371/journal.pone.0149541.

49. Sakoulas G, Moise PA, Casapao AM, Nonejuie P, Olson J, Okumura CY, et al. Antimicrobial salvage therapy for persistent staphylococcal bacteremia using daptomycin plus ceftaroline. Clin Ther. 2014;36:1317-33. doi: 10.1016/j.clinthera.2014.05.061. 


\begin{tabular}{|c|c|c|c|c|c|}
\hline & Tedizolid & Oritavancin & Dalbavancin & Ceftaroline & Ceftobiprole \\
\hline Drug class & Oxazolidinone & \multicolumn{2}{|c|}{ Lipoglycopeptide } & \multicolumn{2}{|c|}{ Cephalosporin } \\
\hline Spectrum & $\begin{array}{l}\text { Most Gram positive } \\
\text { bacteria, including } \\
\text { anaerobes, } \\
\text { streptococci, } \\
\text { staphylococci and } \\
\text { enterococci }\end{array}$ & \multicolumn{2}{|c|}{$\begin{array}{l}\text { Most Gram positive bacteria, including } \\
\text { VRE ; small colony-variants of S. aureus, } \\
\text { mecC+ MRSA; VRSA (oritavancin); and } \\
\text { some VISA/hVISA }\end{array}$} & \multicolumn{2}{|c|}{$\begin{array}{l}\text { Most Gram positive bacteria, including meticillin-resistant } \\
\text { staphylococci } \\
\text { Enterobacteriaceae (although not those with ESBL or } \\
\text { ampC) }\end{array}$} \\
\hline Pharmacokinetics & $\begin{array}{l}\text { Bio-availability, } 91 \% \\
\text { Half life, } 12 \mathrm{~h} \\
\text { Extensive tissue } \\
\text { distribution } \\
\text { Protein binding } 80 \%\end{array}$ & $\begin{array}{l}\text { Half life }>250 \mathrm{~h} \\
\text { Extensive tissue } \\
\text { distribution } \\
\text { Protein binding } 90 \%\end{array}$ & $\begin{array}{l}\text { Half life } 350 \mathrm{~h} \\
\text { Extensive tissue } \\
\text { distribution } \\
\text { Protein binding } \\
95 \%\end{array}$ & $\begin{array}{l}\text { Half life } 2 \mathrm{~h} \\
\text { Good tissue distribution } \\
\text { Protein binding } 20 \% \\
\text { Time/MIC }\end{array}$ & $\begin{array}{l}\text { Half life } 3.5 \mathrm{~h} \\
\text { Good tissue distribution } \\
\text { Protein binding } 16 \% \\
\text { Time/MIC }\end{array}$ \\
\hline Dosage & 200 mg daily, IV or PO & $\begin{array}{l}1200 \mathrm{mg} \text { IV, only } \\
\text { one dose }\end{array}$ & $\begin{array}{l}1000 \mathrm{mg} \text { IV day } 1, \\
500 \mathrm{mg} \text { IV day } 8\end{array}$ & $600 \mathrm{mg}$ IV 2 times per day & 500 mg IV 3 times per day \\
\hline Approved for & ABSSSI & \multicolumn{2}{|l|}{ ABSSSI } & \multicolumn{2}{|c|}{ ABSSSI and community-acquired pneumonia } \\
\hline Weaknesses & $\begin{array}{l}\text { Bacteriostatic } \\
\text { Cost }\end{array}$ & \multicolumn{2}{|l|}{$\begin{array}{l}\text { Only IV } \\
\text { Cost }\end{array}$} & $\begin{array}{l}\text { Only IV } \\
\text { Cost }\end{array}$ & $\begin{array}{l}\text { Only IV } \\
\text { Cost }\end{array}$ \\
\hline Strengths & $\begin{array}{l}\text { Oral drug } \\
\text { Tissue diffusion } \\
\text { No dose adjustment } \\
\text { for renal failure } \\
\text { Safety profile better }\end{array}$ & \multicolumn{2}{|c|}{$\begin{array}{l}\text { Bactericidal } \\
\text { Long half life } \\
\text { Convenient dosing } \\
\text { Safety profile } \\
\text { Reduce duration of inpatient stay }\end{array}$} & $\begin{array}{l}\text { Bactericidal } \\
\text { Safety profile } \\
\text { Some Gram negative } \\
\text { coverage }\end{array}$ & $\begin{array}{l}\text { Bactericidal } \\
\text { Safety profile } \\
\text { Some Gram negative } \\
\text { coverage }\end{array}$ \\
\hline
\end{tabular}




\begin{tabular}{|c|c|c|c|}
\hline & $\begin{array}{l}\text { than linezolid } \\
\text { Active against } c f r+S \text {. } \\
\text { aureus }\end{array}$ & & \\
\hline Comments & $\begin{array}{l}\text { May be useful for CNS } \\
\text { and osteo-articular } \\
\text { infections }\end{array}$ & $\begin{array}{l}\text { May be useful for osteo-articular, } \\
\text { bloodstream, and foreign body-related } \\
\text { infections }\end{array}$ & $\begin{array}{l}\text { May be useful for bloodstream infections, including } \\
\text { endocarditis } \\
\text { Ceftaroline under development as a combination with } \\
\text { avibactam }\end{array}$ \\
\hline
\end{tabular}

ABSSSI, Acute bacterial skin and skin structure infections; CNS, central nervous system ; ESBL, Extended spectrum $\beta$-lactams; h, hours; IV, intravenous ; PO, orally; VISA/hVISA, (heteroresistant) vancomycin-intermediate S. aureus; VRE, vancomycin-resistant enterococci; VRSA, vancomycin-resistant S. aureus. 
Table 1. Characteristics of newer drugs included in this review 